home for nearly two years, they also protected the project's working space and nurtured its contents by bringing to my attention otherwise little-known maps and atlases from their rich collection. Finally, the painstaking task of transforming handwritten text into readable typescript and setting all the type for eighty-nine maps was done by the staff of the Chair of Ukrainian Studies at the University of Toronto.

As important as is human support, projects such as theHistorical Atlas of East Central Europe would have been impossible without significant financial commitments. The project was initially made possible through two grants from the So cial Sciences and Humanities Research Council of Canada and smaller grants from the Centre for Russian and East European Studies at the University of Toronto and the Stephen B. Roman Foundation in Toronto. The support from these institutions provided for professional leave and for the prepara tion of the manuscript and draft maps. The penultimate stage of the project, which required expensive cartographic scribing and preparation of camera-ready plates, was made possible by a generous grant from the National Endowment for the Humanities, an independent federal agency in Washington, D.C. When we were ready for publication, the final stage of the project was made possible by the professionalism of the directorate and staff at the University of Washington Press. I am especially grateful to the copyeditor, Leila Charbonneau.

I am greatly indebted to all of the above individuals and institutions, whose wise counsel has contributed to making this work better than it otherwise would have been. Nonetheless, whatever shortcomings remain are my sole responsibility. This project has, since the beginning, been both demanding and exciting. Hopefully, the result in the form of this Historical Atlas of East Central Europe will be a useful tool to help students and the public at lar ge understand better this still relatively unknown but important area of the world.

Paul Robert Magocsi

Toronto, Ontario

January 1993

\title{
Note to the Second Revised and Expanded Edition
}

The original edition of the Historical Atlas of Central Europe (reprinted, with corrections, in 1995) seems to have fulfilled its purpose: to introduce a wide variety of people to that important but often little-known part of the world. I am particularly gratified by the praise and constructively critical remarks of the seventy-five reviewers, in seventeen countries, who took the time to evaluate the atlas in the publications for which they write. Many of their suggestions/emendations have been incorporated into this revised edition.

With this background in mind, it was much easier for me to respond favorably to the request of the publisher, the University of Washington Press, to prepare a revised edition that would coincide with the dawn of the new millennium. The first edition had been conceived during the second half of the 1980s before the enormous changes ushered in by therevolutions of 1989, which of course profoundly affected precisely those regions covered in this volume. A substantively revised edition therefore seemed necessary to retain the book's value as an introductory reference tool.

The perceptive reader may have already noticed that this re vised edition has a new title, Historical Atlas of Central Europe. The publisher picked up on a suggestion I had made in the in- troduction to the first edition (p. xi) that in purely geographical terms the territory covered in this volume should more properly be referred to as Central Europe. It has also become clear since 1989 that the articulate elements in many countries of this region consider eastern or even east-central to carry a negative conno tation and prefer to be considered part of Central Europe. Since, in fact, none of the various terms - western, central, eastern, east-central, northern, or southern Europe - has precise bound aries, and since the definitions given to these terms vary from author to author, the choice of Central Europe based simply on geographical criteria would seem as valid, if not more so, than any other term. Moreover, if Central Europe responds to the pref erence of the populations of the countries in question, this would seem to lend even greater credence to the terminological choice.

Aside from some corrections in the text and on some of the maps from earlier periods, the most substantive changes in this revised edition relate to the twentieth century. There are twenty new maps and the equivalent of eleven new chapters. The new maps fall into two categories: individual countries, and specific themes covering the entire region. Of the twelve new individual country maps, all but one (Austria) deal with countries that gained (or regained) their independence in the 
course of the 1990s: Lithuania, Belarus, Ukraine, Moldova, Czech Republic, Slovakia, Slovenia, Croatia, Bosnia-Herzegovina, Macedonia, and the new Yugoslavia. The new thematic maps basically follow upon subjects treated in earlier periods. These include developments and changes during the twentieth century in population, ethnolinguistic distribution, international and internal boundaries, education, and the Catholic and Orthodox churches. The only new non-twen tieth century map is of the Teutonic Order, which appears in Chapter 6.

Every effort has been made to maintain consistency in the design and symbology between the revised edition (computer-generated) and the original edition (hand-drawn) maps. The University of Toronto's Office of Cartography is again responsible for the final maps, although that department is now under the direction of Byron Moldofsky, with the cartographic work being carried out by Jane R. Ejima, Mary-Ellen Maybee, and Daniel Spring. I am thankful to them for maintaining the high aesthetic and technical standards set by the first edition, as well as to Bogdan Czaykowski (University of British Columbia), Mladen Klemenčić (Krleža Lexicographical Institute, Zagreb), and to several University of Toronto colleagues - Jerzy Borżęcki, Marko Bulatović, Jack Fairey, Jüri Kivimae, Andrij
Makuch, Aleksander Panev, Andrew Rossos, Piotr Wróbelwho were extremely helpful in directing me to data and for reviewing specific maps. The production stage was enhanced by the accuracy of Yana Filippenko, who inputted the text, and of Leila Charbonneau, Julidta Tarver, and Marilyn Trueblood, who successfully coordinated the production of a volume carried out in cities located in three countries and two conti nents-from Toronto to Seattle to Hong Kong and back.

Aside from intellectual and technical skills, the publication of atlases in full color is costly and requires substantial funding. In that regard, the appearanceof this revised and expanded edition of the atlas has been made possible by a grant from the University of Washington Press, which was matched by grants from several bodies at the University of Toronto: the Office of the Vice-President for Research and International Relations, the Office of the Dean of the Faculty of Arts and Sciences, the Department of History, and the Department of Political Science. To the heads of all those institutions I am particularly grateful.

Paul Robert Magocsi Toronto, Ontario October 2001

\section{Note to the Third Revised Edition}

More than a decade and a half has gone by since the appearance of the second edition of the Historic Atlas of Central Europe. Interest in this part of the world remains high, so that when the second edition needed to be reprinted, it was decided instead to undertake a third revised edition to be published solely by the University of Toronto Press.

The text of the entire book has been revised, quite substantially in some chapters, and most especially the statistical tables for individual countries which now include data collected at the outset of the second decade of the twenty-first century. Because of political changes, Montenegro and Kosovo are now treated as distinct countries with a new map of Monte negro and appropriate changes on several other maps. The Map sources and Bibliography have been expanded to reflect the appearance of several new cartographic works on Central Europe and its component countries. Finally, the comprehensive index has been amended to include the changes made on the maps and in the text.

The author is particularly grateful to the 80 reviewers of the first edition and the 15 reviewers of the second revised edition, many of whom made suggestions and emendations that have been incorporated into this third revised edition.
Among colleagues whose expertise has been beneficial to certain chapters and maps in the present edition are Robert Austin (University of Toronto) and Tomasz Kamusella (University of St. Andrews, Scotland). Nadia Zavorotna (University of Toronto) has been particularly helpful in obtaining resources for the most recent census data.

This project is fortunate to have the changes on the existing digital maps made by the University of Toronto's Office of Cartography under the direction of Byron Moldofsky. All of the original hand-drawn maps were digitized by Branislav Švorc. The layout and corrections on some non-digital maps was undertaken by John Beadle. The inputting of the complicated changes in the text and statistical charts was carried out with admirable competency by Ivanna Prots. It is my hope that the third revised edition of the Historical Atlas of Central Europe will be as helpful to a cohort of new users as the earlier editions have been for previous readers.

Paul Robert Magocsi
Toronto, Ontario
April 2017 